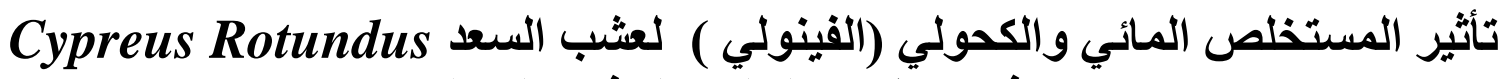 في الانقسام الخلوي لجذئور البصل \\ | (نتصار عبل الله حسن*
}

استلام البحث 19، ايلول، 18 2012، 2013

قبول النشر 18، حزيران، 2013

أجريت هذه الدراسة لاختبار تأثثر المستخلص المائي و الكحولي(الفينولي) لعشب السعد في الانقسام الخلوي

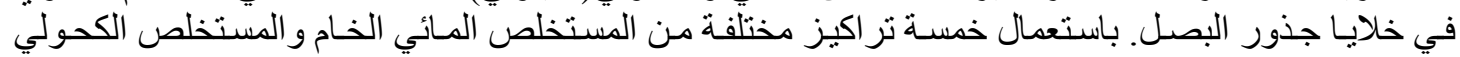

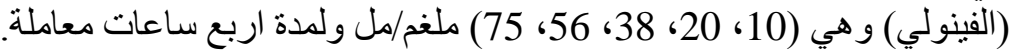

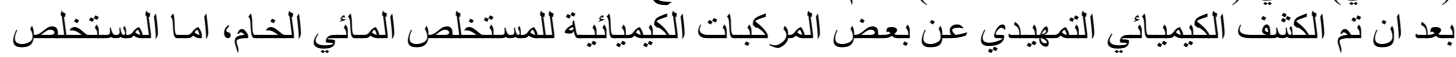

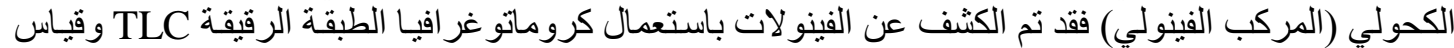
عامل الاعاقة RF ودرجة الانصهار وقياس الامتصناصية.

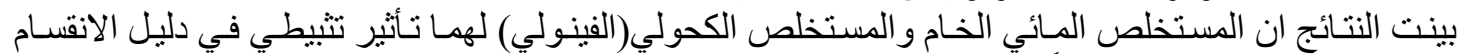

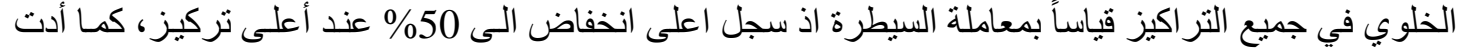

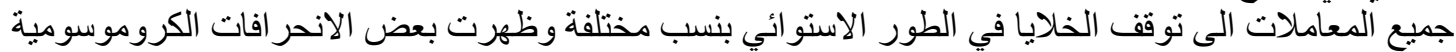

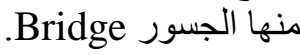

الكلمات المفتاحية : عشب السعد ، دليل الاتقسام ، جذور البصل

AFlatoxin B1 عالية في كنس الجذور الحرة تماثل أو تقارب من الحن

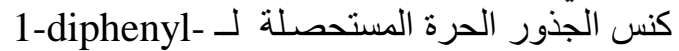

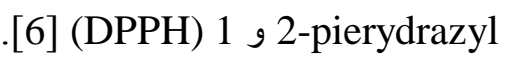

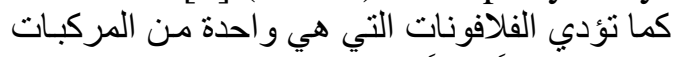

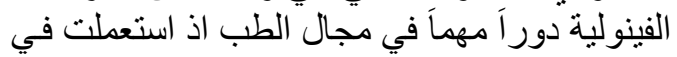
علاج الاورام السرطانية وكذللك علاج الكبد [7].

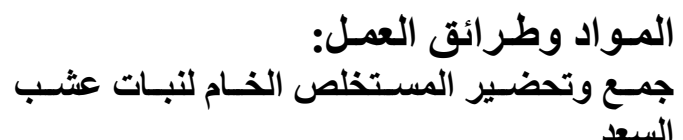

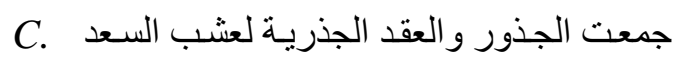
مـ rotunds

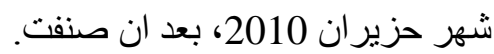

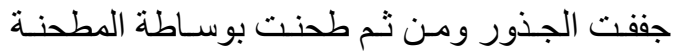

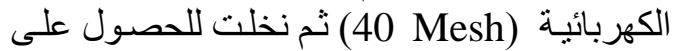

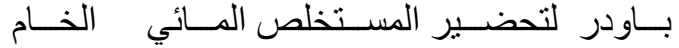
و الكحولي(الفينولي ) لعشب السعد.

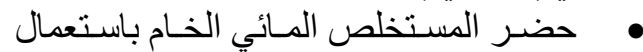

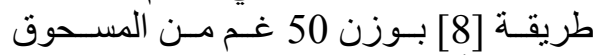

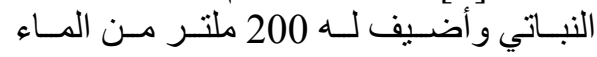
المقطر وترك مدة 24 ساعة في جهاز المازج المجاء

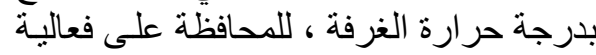

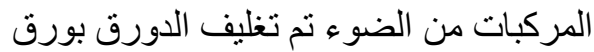

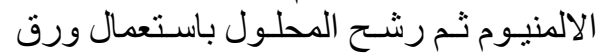

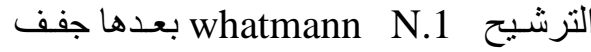

المقدمــة:ة

نظـر اً لأهميـة الاعثـــاب و النباتـات الطبيـة كونهـا

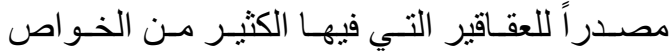

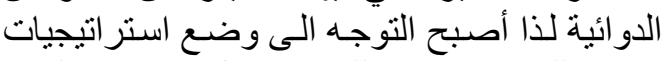

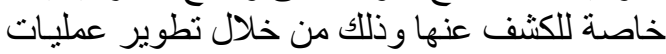

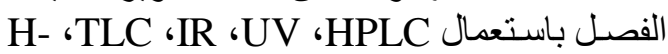

.[1] NMR

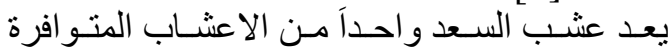

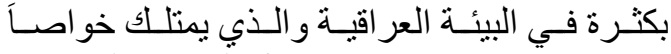
علاجية عديدة اذ وجد من خـلال الفحص الكي الكيميائي

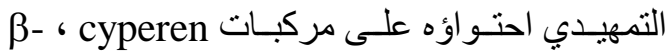
'cyperol ، sesquiter penoids ، sitosterol vitamin ' saponin ، flavonol glycosids . $[2,3]$ essential oil ، polyphenol ، c لنبـات عشـب السـعد أهميـة طبيـة متعددة اذذ أظهـر

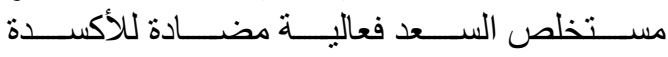
Mitochondrial من خلال منع فئع Antoxidation peroxdation FeSo 4 /ascorbate

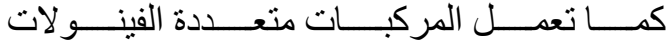
polyphenol Micronuclei المحيطي و هذا التأثير يمنع الضرر لـ لـ DNA و التي

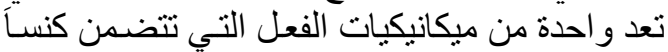
للجذور الحرة [5ن]. سجل المستخلص الكحة الكولي (المثيلي) لعشب السعد

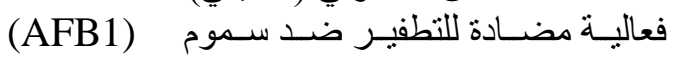




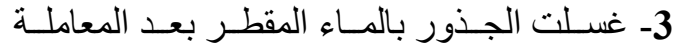

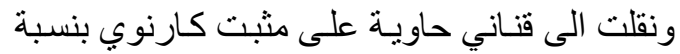

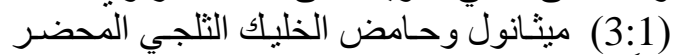
آنياً وتركت لمدة 6-24 ساعة سحة

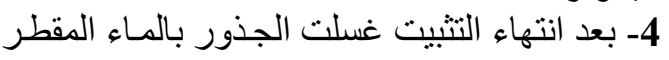

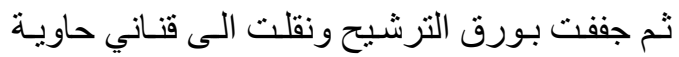

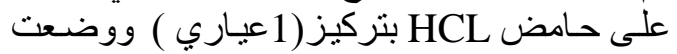
في فرن درجة حر ارته 60 مُ لمدة 10 دقائق.

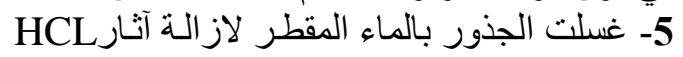

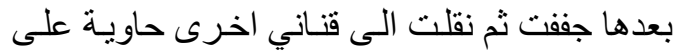

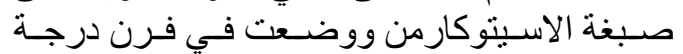

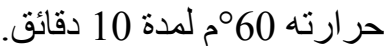

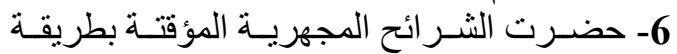

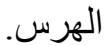

اللمستخلصين التأثيرات الانقسام الخيطي لجذية الخلوية

حضـرت خمســة تر اكيـز مختلفـة مـن المسـتخلص

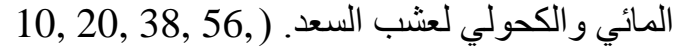

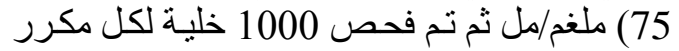
ولكل التر اكيز وطبقت الدر اسة نفسها على مكررات دليل الانقسام \%= دليل الطور = = عدد خلايا المنقسمة دليل الحالات الثاذة \%=

التحليل الاحصـائي: حلات نتـائج الدر اسـة احصـائياً

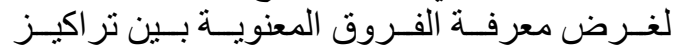

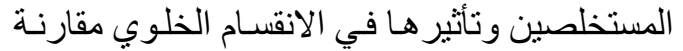

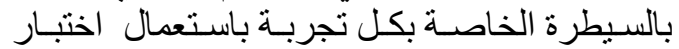
دنكن متعدد الحدود Duncan`s multiple test و البرنامج الاحصنئي الجاهز SPSS.

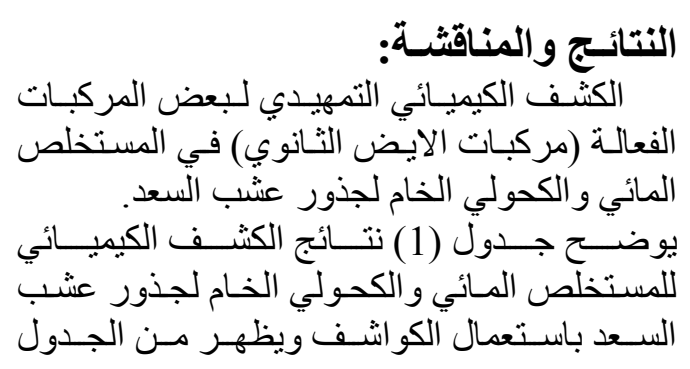

الر اشح باستعمال حاضنة مروحيـة للحصول

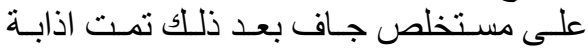
المستخلص النـاتج في حجم معلوم من المـاء

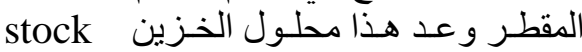
solution

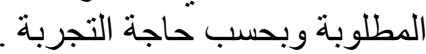

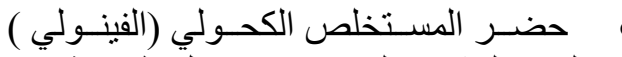

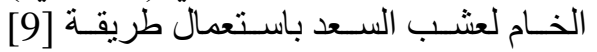

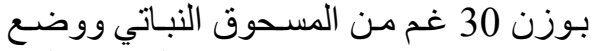

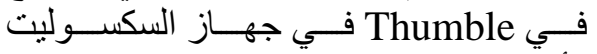

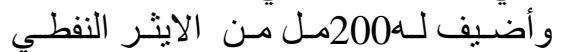
petrolum ether لمـدة 6 سـاعات بعـدها لالفيا

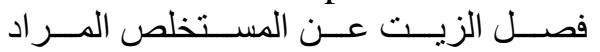

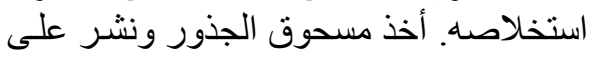

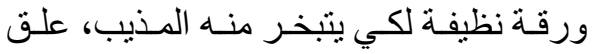

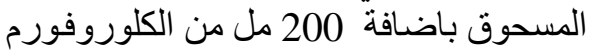

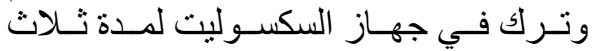

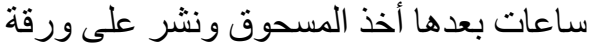

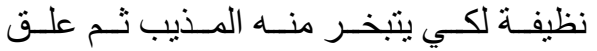
المسـوق باضـافة الايثـانول و المساء المقطر

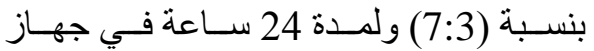

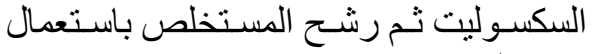

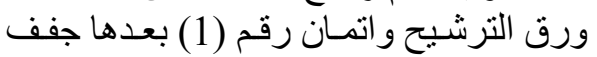

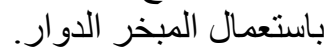

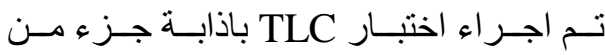

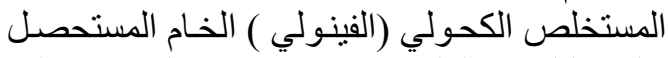

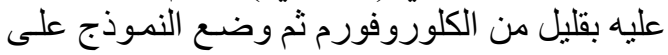

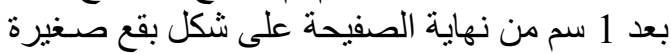

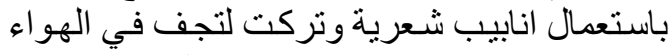

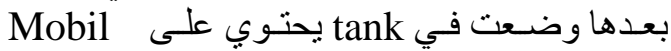

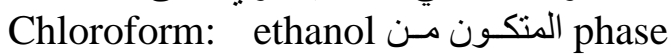
بنسبة (9:1) حيث ظهرت كما في الصورة بقعتان

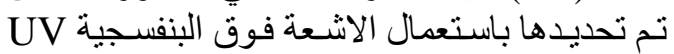

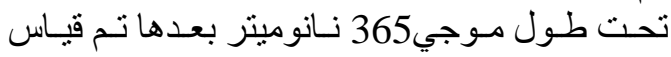

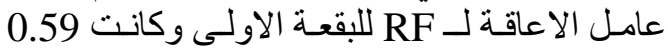
و الثانية كانت

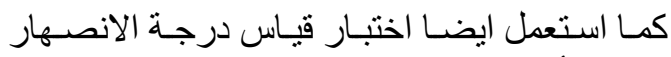

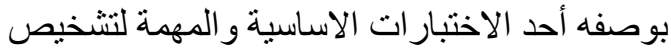
المركبات اذ ان لكل مركب درجـة انصـهار خاصـة الأسة

ـ ـ تحضير جذور البصل باستعمال طريقة [10].

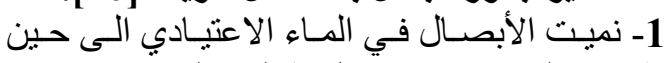

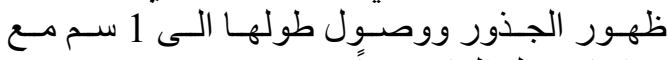
مر اعاة تبديل الماء يو يومياً.

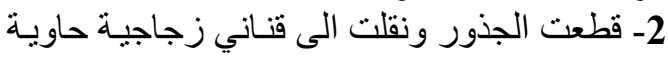

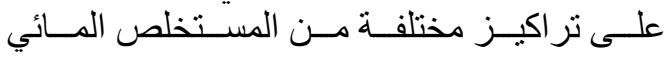
و الكحولي وبو اقع ثلاثة مكرر ات لكل تركيز فضلا عن الى السيطرة ولمدة اربع ساعات. 


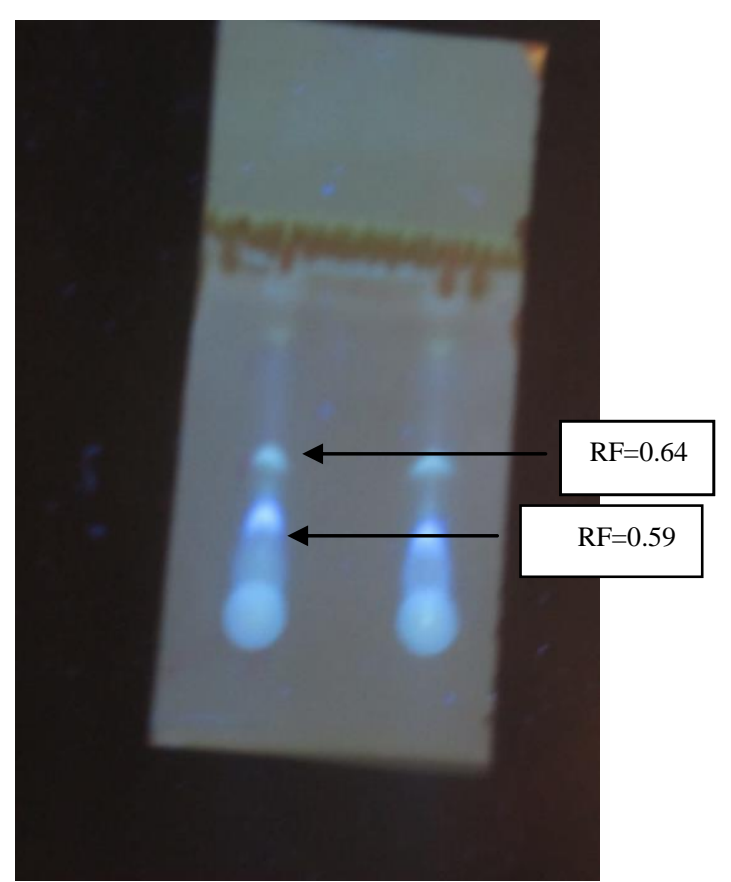

شكل -1- الكثف التمهيدي عن المركبات الفينولية المستخلصة من جذور عثب السعد باستعمال

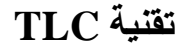
على طول موجي 365 نانوميتر

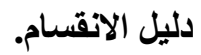

كانت قيمة دليل الانقسام في جذور السيطرة 9.42

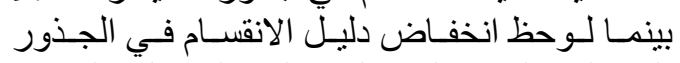

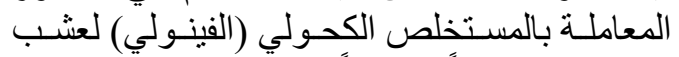

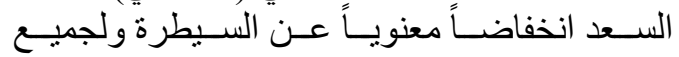

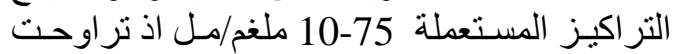

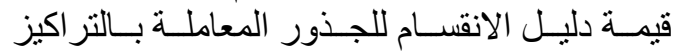
المذكورة من 86.25-43040 للمستخلص الكحولي

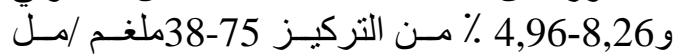

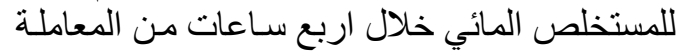
وبفرق معنـوي بمستوى احتماليـة بالسيطرة (جدول2-3و).

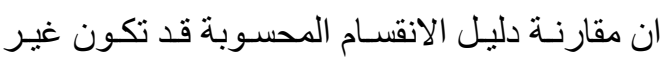

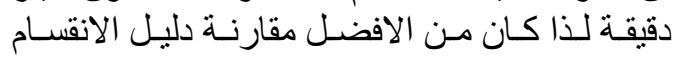

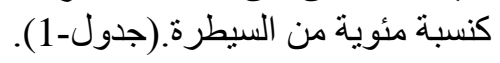

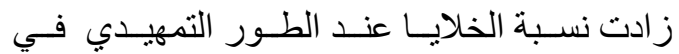
الجذور المعاملة بالمستخلص المائي و الكحولي عما

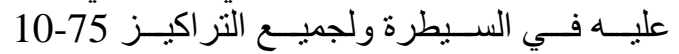

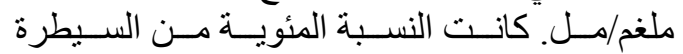

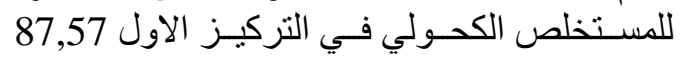

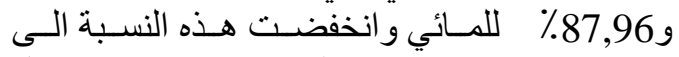

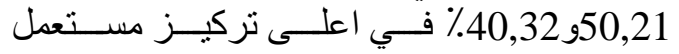

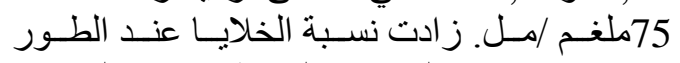

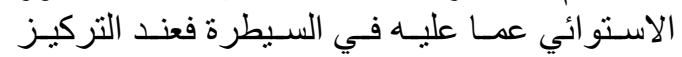

احتو اء المستخلص المائي و الكحولي لجذور عشب التباتب التبات

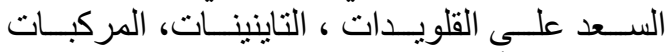

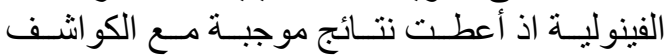
المستعطلة.

جدول (1): الكثف الكيميائي التمهيدي للمستخلص المائي الخام والكحولي (الفينولي )

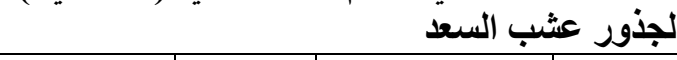

\begin{tabular}{|c|c|c|c|c|}
\hline \multicolumn{2}{|c|}{ المستخلص } & \multirow[t]{2}{*}{ دليل الكثف } & \multirow[t]{2}{*}{ الكاثف المستعمل } & \multirow{2}{*}{ الفركال } \\
\hline كحولي & مائي & & & \\
\hline+ & + & راسب بني & كاثف در اجندروف & \multirow{3}{*}{ القلويدات } \\
\hline \multirow[t]{2}{*}{+} & - & راسب & كاشف ماير & \\
\hline & + & راسب بني & كاشف و اكنر & \\
\hline+ & + & لون اخضر & كلوريد الحديديك 1\% & التانينات \\
\hline+ & + & راسفر & هيدروكسبد البوتاسيوم كحول & الفلافونات \\
\hline
\end{tabular}

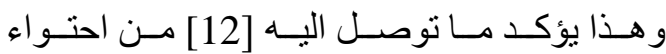

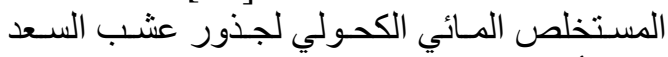

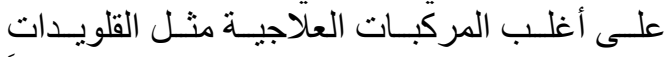

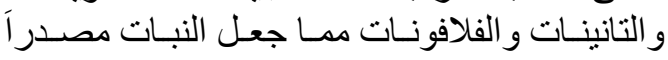

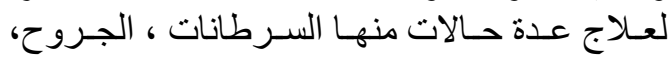

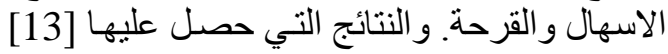

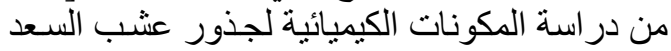

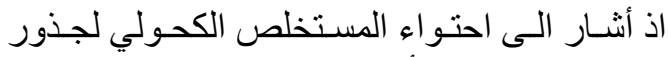

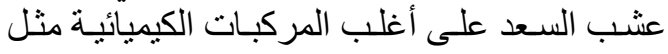

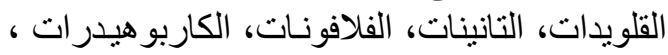

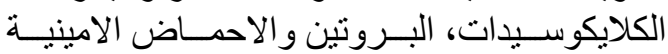

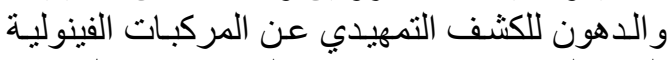

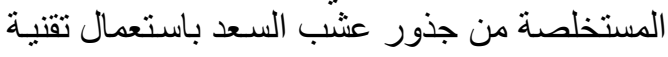
كرومونو غر افيـا الطبقـة الرقيقـة chromatography TLC

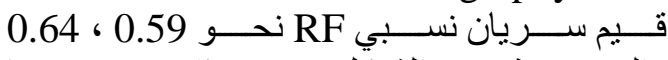

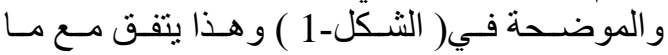
توصل اليه [9].

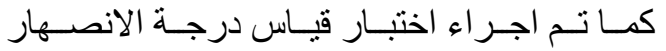

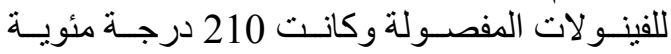

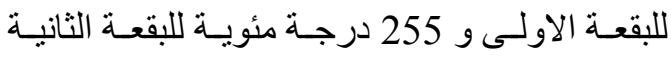

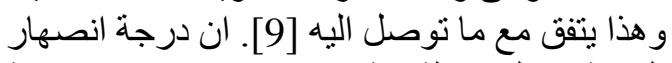

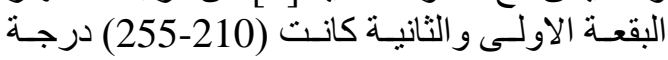

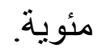




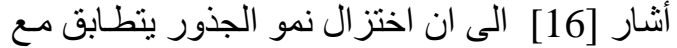

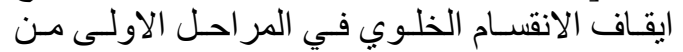

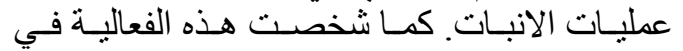

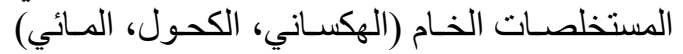

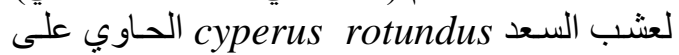

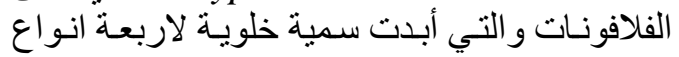

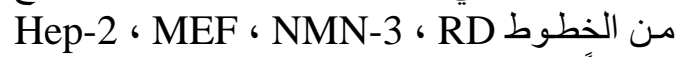

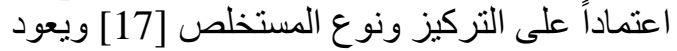

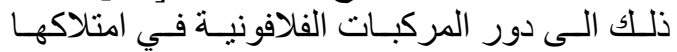

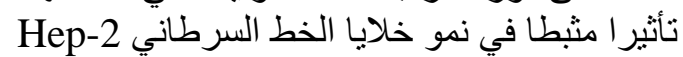

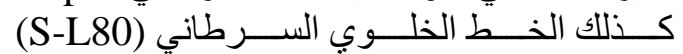

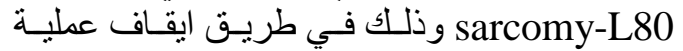

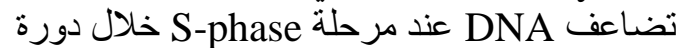
حياة الخلية [18] كما تؤثر هذه المركبات في الآلية

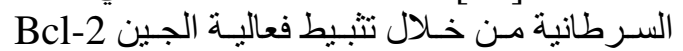
ونتيجة للخلل الحاصل في هذا الجين تدخل الخدالية الخلية

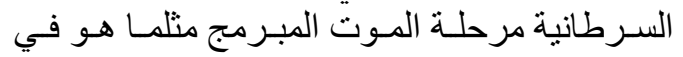

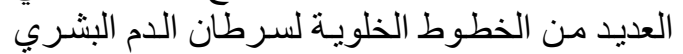
.[19] Human Leukemie cell lines
الاول كانت 125.35 \% وز ادت الى 160.51 \%ان

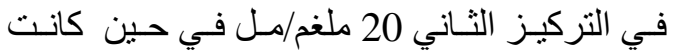

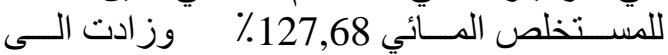

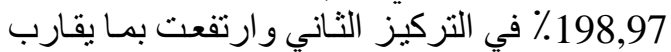

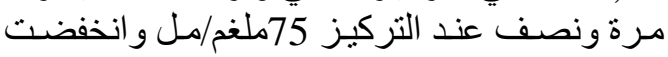

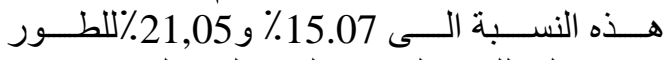

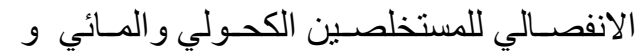

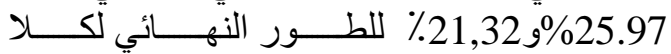
المستخلصين المئ.

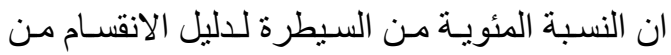

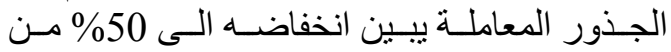

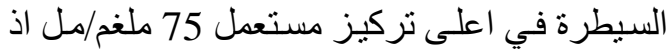

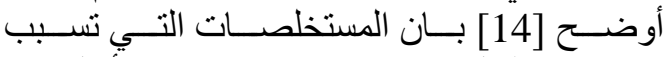

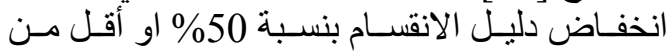

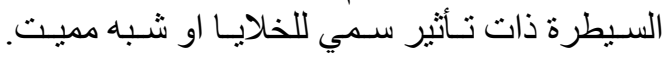

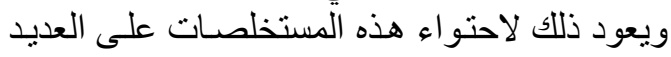

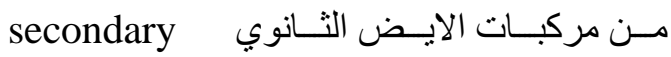

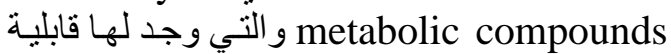

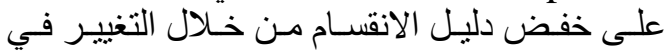

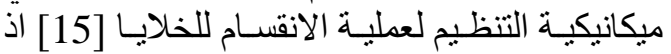

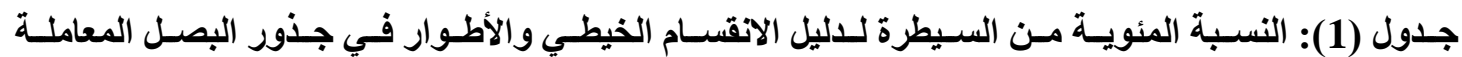

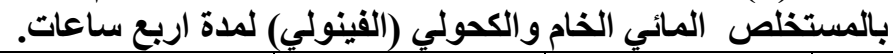

\begin{tabular}{|c|c|c|c|c|c|c|c|c|c|c|}
\hline \multicolumn{2}{|c|}{ النهائي.\% } & \multicolumn{2}{|c|}{ الطور الانفصالي. } & \multicolumn{2}{|c|}{ الطور الاستوائي ٪ } & \multicolumn{2}{|c|}{ الطور التمهيدي٪ } & \multicolumn{2}{|c|}{ دليل الانقسام٪ } & \multirow{2}{*}{ التركيز } \\
\hline المائي & الكحولي & المائي & الكحولي & المائي & الكحولي & المائي & الكحولي & المائي & الكحولي & \\
\hline 61,27 & 87.10 & 68,46 & 65.19 & 127,68 & 125.53 & 95,73 & 104.25 & 87,96 & 87.57 & 10 \\
\hline 50,72 & 69.33 & 48,78 & 41.38 & 198,97 & 160.51 & 96,2 & 96.79 & 77,80 & 72.71 & 20 \\
\hline 34,90 & 42.18 & 29,31 & 25.17 & 224,48 & 118.08 & 86,03 & 90.00 & 67,15 & 65.49 & 38 \\
\hline 23,74 & 31.64 & 21,26 & 20.63 & 280,53 & 212.06 & 66,84 & 75.57 & 55,85 & 55.20 & 56 \\
\hline 21,32 & 25.97 & 21,05 & 15.07 & 301,76 & 250.07 & 58,03 & 62.40 & 40,32 & 50.21 & 75 \\
\hline
\end{tabular}

\section{دليل الطور}

الطور التمهيدي: تقاربت نسبة الطور التمهيدي في الطي

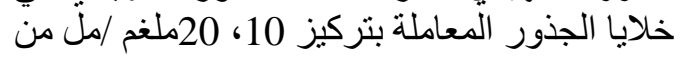

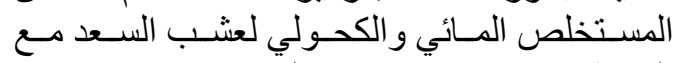

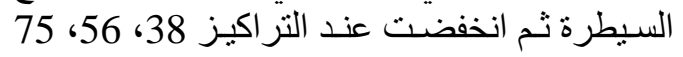

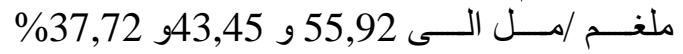

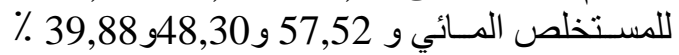
للمستخلص الكحولي وكان الفرق معنوياً بين خلايـا

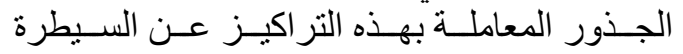

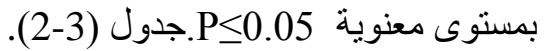
الطور الاستو ائي: زادت نسبة الخلايـا عند الطور

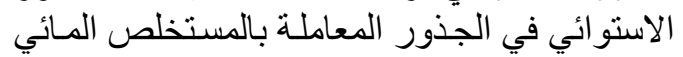

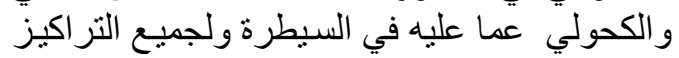

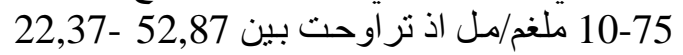

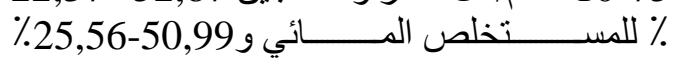

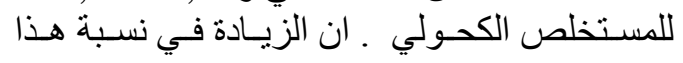

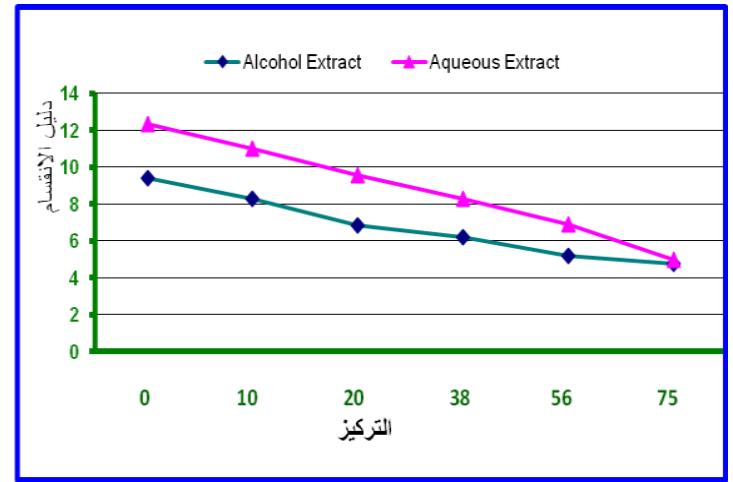

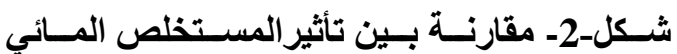
والكحولي (الفينولي ) في دليل الانقيرام 


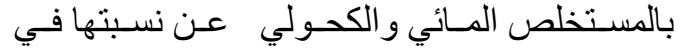

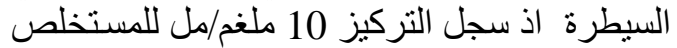

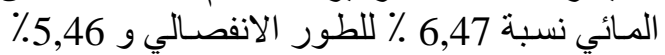

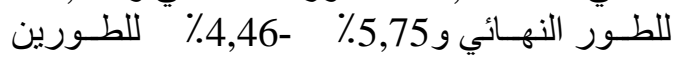

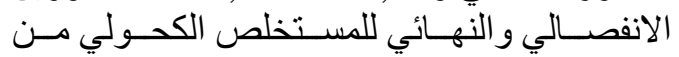

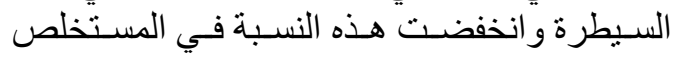

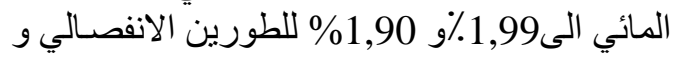

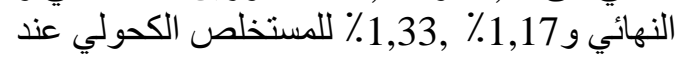
المعاملة بالتركيز 75 ملغم/مل.

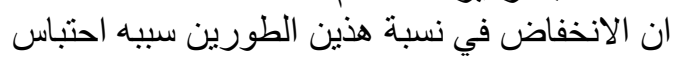

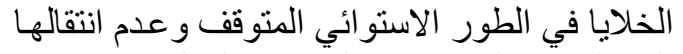

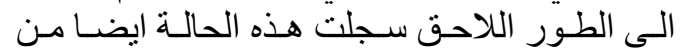

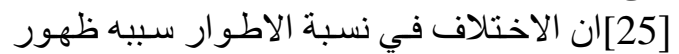

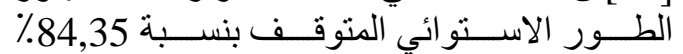
للمستخلص المائي و 80,45\% للمستخلص الكي الكحولي ومن ثم ادت الى انخفاض نسبة هذين الطورين كمـا

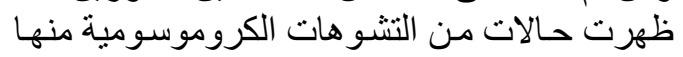
ظهـور الجسـور الكروموسـومية اذ ســلــ التركيـز

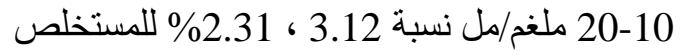

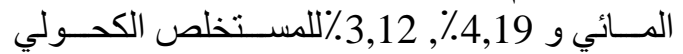

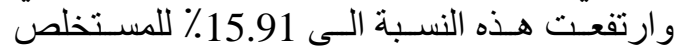
المائي و 14,92\% بللمستخلص الكحولي عند المعاملـة

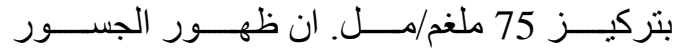

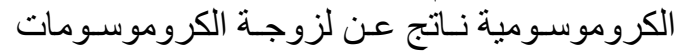

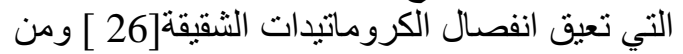

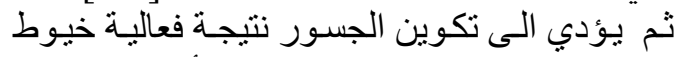
المغزل في سحب الكروموسومات للأقطاب ويؤدي

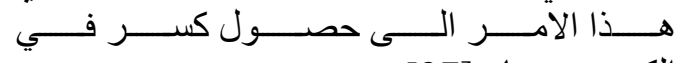

الطور مقارنـة بالسيطرة يعود الى احتبـاس الخلايـا

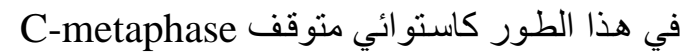
وفي جميع التر اكيز. اذ كانت نسبة الطور الاستوائي

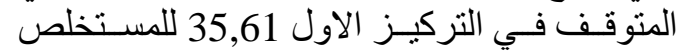

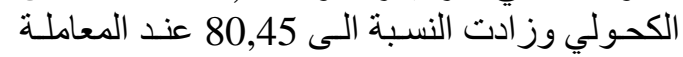

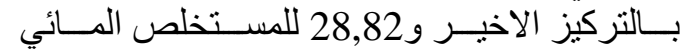

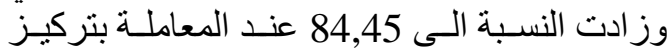

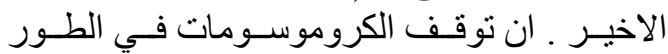

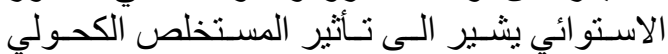

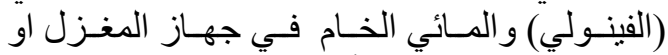
مكوناته وشخص هذا التأثنير في المركبات الفينولية فئن

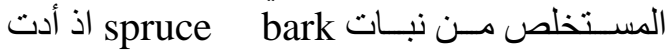

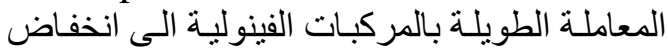

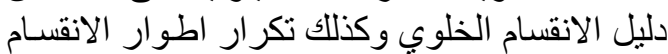

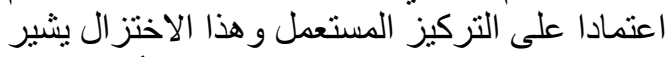

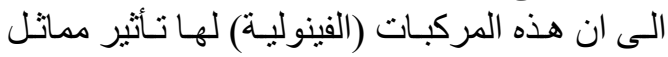

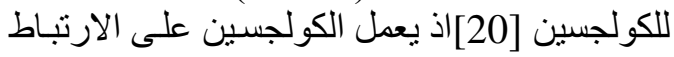

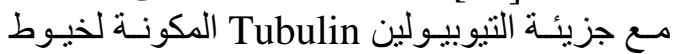

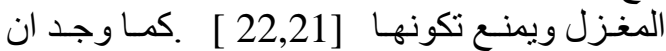

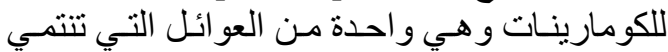

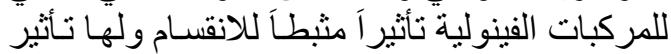

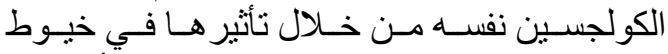

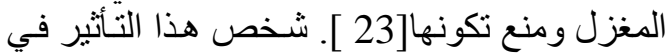
بعض المركبات الفينولية اذ أدت الى تأثير في انبات

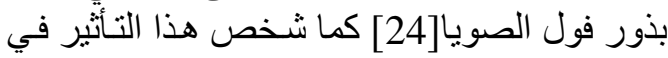

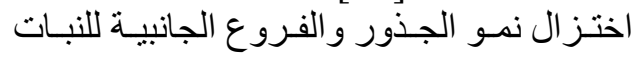

.[5]Brassica oleraceael

\section{الطـوران الانفصـالي والنهـائي: انخفضــت نسـبة}

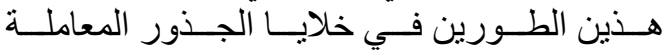

جدول (2):تاثير المستخلص المسائي لجذور عشب السـعد في دليل الانقسـام الخيطي والنسبة المئويـة لأطوار

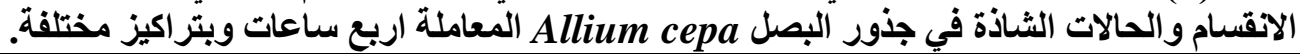

\begin{tabular}{|c|c|c|c|c|c|c|c|}
\hline \multicolumn{3}{|c|}{ دليل الحالات الشاذة \% } & \multicolumn{3}{|c|}{ دليل الطور \% } & \multirow[b]{2}{*}{ دليل الانقسام } & \multirow[b]{2}{*}{ التركيز } \\
\hline جسور & استوقوائي & النهائي & الانفصالي & الاستو ائي & التمهيدي & & \\
\hline- & - & 8.91 & 9.45 & 17.52 & 65 & $0.60 \pm 12.30 \mathrm{a}$ & 0.00 \\
\hline 3.12 & 28.82 & 5.46 & 6.47 & 22.37 & 62.23 & $0.25 \pm 10.82 \mathrm{ab}$ & 10 \\
\hline 2.31 & 39.91 & 4.52 & 4.61 & 34.86 & 60.63 & $0.84 \pm 9.57 b c$ & 20 \\
\hline 13.01 & 52.24 & 3.11 & 2.77 & 39.33 & 55.92 & $0.49 \pm 8.26 \mathrm{~cd}$ & 38 \\
\hline 12.62 & 77.33 & 2.12 & 2.01 & 49.15 & 43.45 & $0.40 \pm 6.87 \mathrm{~d}$ & 56 \\
\hline 15.91 & 84.35 & 1.90 & 1.99 & 52.87 & 37.72 & $0.22 \pm 4.96 \mathrm{e}$ & 75 \\
\hline
\end{tabular}

الاحرف المختلفة تمثل فروقاً معنوية عند مسنوى احتمالية (P>0.05) 
جدول (3):تأثثر المستخلص الكحولي لجذور عشب السعد في دليل الانقسـام الخيطي والنسبة المئويـة لأطوار

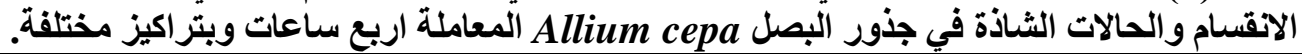

\begin{tabular}{|c|c|c|c|c|c|c|c|}
\hline \multicolumn{3}{|c|}{ دليل الحالات الشاذة \% } & \multicolumn{3}{|c|}{ دليل الطور \% } & \multirow[b]{2}{*}{ دليل الاتقسام } & \multirow[b]{2}{*}{ التركيز } \\
\hline جسور & متوقتف & النهائي & الانفصالي & الاستوائي & التمهيدي & & \\
\hline- & - & 5.12 & 8.82 & 20.39 & 63.91 & $0.25 \pm 9.42 \mathrm{a}$ & 0.0 \\
\hline 4.19 & 35.61 & 4.46 & 5.75 & 25.56 & 66.63 & $0.73 \pm 8.25 b$ & 10 \\
\hline 3.12 & 48.52 & 3.55 & 3.65 & 32.73 & 61.86 & $0.49 \pm 6.85 c$ & 20 \\
\hline 18.02 & 66.15 & 2.16 & 2.22 & 40.39 & 57.52 & $0.31 \pm 6.17 \mathrm{~cd}$ & 38 \\
\hline 15.26 & 45.68 & 1.62 & 1.82 & 43.24 & 48.30 & $0.49 \pm 5.20 \mathrm{de}$ & 56 \\
\hline 14.92 & 80.45 & 1.33 & 1.17 & 50.99 & 39.88 & $0.13 \pm 4.73 \mathrm{e}$ & 75 \\
\hline
\end{tabular}

6. Kilani, S.; Abdelwahed, A.; Chraief, I.; Ben, A.R.; Hayder, N.; Hammami, M.; Ghedira, K. and Chekir-Ghedira, L. 2005. Chemical composition, antibacterial and antimutagenic activities of essential oil from Tunisian Cyperus rotundus. J. Essent. Oil. Res, 17: 695-700.

7. Birt, F.D.; Hendrich, S. and Wang, W. 2001. Dietary agents in cancer prevention: Flavonoids and isoflavonoids. Pharm. Therap. USA,90: 157-177.

8. Chaniago, I.; Taji, A.; Kristiansen,P. and Jessop,R. 2008. Soybean Root-Tip-Cell Mitosis under the influence of Aqueous extracts of three weed species . J. Akta Agrosia, 11(1) : 1410-3354.

9. Dilipkumar, P.; Santanu, D. and Abhijit, S. 2009. Evaluation of CNS Activities of Ethanol extract of Roots and Rhizomes of cyperus Rotundus in mice. Act poloniac pharma. Drug. Res, 66(5): 535541.

10. Sharma, A.K. and Sharma, A. 1980. Chromosome techniques theory and practice: $3^{\text {rd }}$ ed., Butter Worth's Company. London. Boston.

11. Becker, W.M.; Kleinsmith, L.J. and Hardin, J. 2003. The World of the Cell. $5^{\text {th }}$ ed., Benjamin Chmmings Publishing Company, Inc. New York.

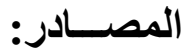

1. Shachi, S.; Member, I.; Jagdamba, S.; Shiv, K.; Member, I and Member, I. 2010. New Terpenoid from Rhizomes of cyperus Scariosus. Inter. J .Chem. engineer .Appl,1(1): 25-30.

2. meena, A.K.: Yadav, A.K.: Niranjan, U.S.: Brijendra, S.; Nagariya A. K and Mansi, V. 2010. Review on cyperus rotundus- A potential Herb. Inter. J .Pharma . Clin. Res, 2(1): 20-22.

3. Surendra, K.S. and Ajay, P.S. 2011. Morphological, Microscopical and Physico-Chemical investigation on the rhizomesof Cyperus rotundus Linn. Res. J . Pharma, Bio . Chem. Sci,2(3): 798-804.

4. Nagulendran, K.R.; Velavan, S.; Mahesh, R. and Hazeena, B. 2007. In vitro Antioxidant activity and Total polyphenolic content of cyperus rotundus Rhizomes. E.J . Chem, 4(3) : 440-449.

5. Yamagushi, M. Q.; Andrade, H.M.; Pardocimo, E.M.; Portilho, G.P.; Bittencourt, A.H.C. and Vestena, S. 2007. Efeito de extractos aguosos de tiririca cyperus routundus L. sobre a germinacao e crescimento de repolho Brassica leeraceae de nabo Brassica Rapal .Rev.cien. fam, 3(1):262 
Family Proteins by Cancer Chemoprevention and Chemotherapy. Curr-Pharm. DES, 10: 1387-1398.

20. Balas, A.;Capraru, G.; Danaila,M. and Popa.,V.I. 2007. Cytogenetic Effects Induced by Phenolic Compounds in Lycopersicon Esculentum Mill. Sec. Gen. Bio. Mol. 187-192.

21. Vaughn, K. C. and Lehnen Jr.; L. P. 1991. Mitolic Disrupter Herbicides. Weed Sci, 39: 450457.

22. Yeong, F.M. 2004. AnaphasePromoting Complex in Caenorhabditis eleyans. Mol. Cell. Bio, 24(6): 2215-2225.

23. Cornman, I. 1946. Alteration of Mitosis by Coumarin and Parasorbic Acid. Am. J. Bot, 33:217.

24. Flảvia, T.C,Elizabeth ,O.O; Joảo,D.R.and Josẻ,R.de Souza.p. 2003.Effect of some phenolic compounds on soybean seed germination and on seed-borne fungi. J. Brazil Arch. Bio. Tech ,46(2):155-161.

25. القيسي، بيداء عامر احمد 2006.تأثير

Convolvulus مستخلصات المديد arvensis L.

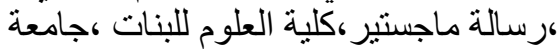

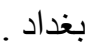

26. Mercykutty, V.C. and Stephan, J. 1980. Adrimycin Induced genetic Toxicity as demonstrated by the Allium cepa test. Cyt, 45: 769-777.

27. Losada, A. and Hirano, T. 2001. Shaping the metaphase chromosome coordination of cohesion and condensation. Bio Essays, 23: 924-935.
12. Banez,S.E.S. 2011. Phytochemical and Pesticidal Properties of Barsanga Cyperus Rotundus Linn. J.JPAIR, 6: 2012-3981.

13. Rai, P.K.; Kumar, R. Malhotra; Y.; Sharma, D. and Karthiyagini, T. 2010. Standardzation and preliminary phytochemical investigation on cyperus rotundus linn Rhizome. Inter J. Res. in Ayu . Pharma, 1(2): 536-542.

14. Antonsie, W.D. 1990. Anlysis of the Cell Cycle in the Root Meristem of Allium cepa Under the Influence of Leda Krin. Folia Histochem Cyto.bio, 26: 79-96.

15. Connock, J.; Bradow, W.J.M.; Legendere, S.L.; Vail, and Menges, $\quad 1987$. Indentification of Volatile allelochemicals from Amaranthus Palmeri S. Wast. J. chem. Eco, 13: 463-472.

16. Friedmann, T. and Horowitz, M. 1971. Biologically Active Substances in Subterranean Parts of Purple Nutsedge. Weed Sci, 19: 398-401.

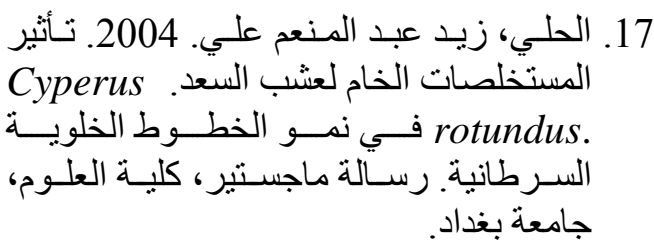

18. Elangovan, V.; Ramamrthy, N.; Balasubramabian, S.; Sekar, N. and Govidsany. 1994.studies on the antiproliferative effect of some naturally occurring bio flavonoidal compounds against human carcinoma of larynx and sarcoma 180 cell lines india. J. pharma, 26:266-269.

19. Pellechia, M. and Read, J.C. 2004. Inhibition of anti-apoptosis Bcl-2 


\title{
Effect of aqueous and alcohol (phenol) extract from cyperus rotundus on mitotic Division in tap roots of Allium cepa.
}

\section{Intisar Abdullah Hassan*}

*College of Sciences for Women/ University of Baghdad.

\begin{abstract}
:
This study was conducted to test the effect of aqueous and alcoholic extracts for cyperus rotundus on the mitosis in tap roots of Allium cepa. the result of general an identical qualitative tests showed contains certain compounds that of crude aqueous and alcoholic extract, Used as five different concentrations of $(10,20.38,56,75) \mathrm{mg} / \mathrm{ml}$ for a period of four hours of treatment.

After the chemical has been detected for some preliminary chemical compounds of the crude aqueous extract, while the alcoholic extract either phenol compound has been detected for phenols using several techniques included the use of thin layer chromatography TLC and measurement of disability factor RF and the degree of fusion and measurement of absorbance.

The results showed that the crude aqueous extract and alcoholic extract and phenol their impact inhibitive as decreased normal division in all concentrations, where it decreased to $50 \%$ of the control treatment at the highest concentration also led all transcription to stop cells in metaphase at different rates and there were some chromosomal aberration including Bridges.
\end{abstract}

